\title{
PENGEMBANGAN SOUND CARD LAPTOP SEBAGAI ALAT PRAKTIKUM FISIKA UNTUK PENENTUAN PERCEPATAN GRAVITASI BUMI
}

\author{
Eka Maryam ${ }^{1}$, Ahmad Fahrudin ${ }^{2}$ \\ Ekamaryam996@gmail.com \\ 1,2Universitas Bina Insan Lubuklinggau, Sumatera Selatan, Indonesia
}

Received: 27 Mei 2020

Revised: 29 Mei 2020

Accepted: 13 Juni 2020

\begin{abstract}
The purpose of this research is to develop a laptop soundcard as a physics practice tool for the determination of Earth grafitational acceleration. The Earth's gravitational force is the power that makes the Earth draw objects to its center. This tool is designed using 3 pieces of copper coil separated by a certain distance. The Data obtained is presented in the form of Time ( $t$ ) which is calculated from the symptoms of induction by magnetic through the coil. When the magnet is dropped, time is measured from the emergence of pulse when the magnet induces the coil using the Audacity software. From the Pulse brings out the results of time in each distance. This research uses development methods with Analysis, Design, Development, Implementation, Evaluation (ADDIE). The laptop's practicum soundcard tool is validated by expert tools for technical aspects and students as a test user. Data collection techniques in this research using poll. Angket is used to measure the feasibility of the development of laptop soundcard equipment. The poll is given to 3 members of the Practicum tools and students as a user. A poll validation analysis uses a Likert scale with a value range of 1 to 5. This results in a practical tool that has a good graphing perceptant measurement accuracy with a $2.33 \%$ error. While the result of validation shows that both validation provides excellent responsiveness so that, practicum soundcardlaptop tool can be used practicum.
\end{abstract}

\begin{abstract}
Abstrak: Tujuan dari penelitian ini adalah untuk mengembangkan soundcard laptop sebagai alat praktikum fisika untuk penentuan percepatan grafitasi bumi. Gaya gravitasi bumi adalah kekuatan yang membuat bumi menarik objek ke pusatnya. Alat ini didesain menggunakan 3 buah lilitan koil tembaga yang dipisahkan oleh jarak tertentu. Data yang diperoleh disajikan dalam bentuk waktu (t) yang dihitung dari gejala induksi oleh magnet yang melalui lilitan. Ketika magnet dijatuhkan, waktu diukur dari munculnya pulsa ketika magnet menginduksi lilitan dengan menggunakan software audacity. Dari pulsa tersebut memunculkan hasil waktu pada masing-masing jarak lilitan. Penelitian ini menggunakan metode pengembangan dengan Analysis, Design, Development, Implementation, Evaluation (ADDIE). Alat praktikum soundcard laptop divalidasi oleh ahli alat untuk aspek teknis dan mahasiswa sebagai uji pengguna. Teknik pengumpulan data pada penelitian ini menggunakan angket. Angket digunakan untuk mengukur kelayakan pengembangan alat praktikum soundcard laptop. Angket diberikan kepada 3 ahli alat praktikum dan mahasiswa sebagi pengguna. Analisis validasi angket menggunakan skala likert dengan rentang nilai 1 sampai 5. Hasilnyan didapakan alat praktikum yang memiliki akurasi pengukuran perceptan grafitasi yang baik dengan error 2,33\%. Sedangkan hasil dari validasi menunjukkan bahwa kedua validasi memberikan responyang sangat baik sehingga, alat praktikum soundcardlaptop dapat digunakan Praktikum.
\end{abstract}

Kata kunci:Pengembangan, alat praktikum soundcard latop,percepatan grafitasi bumi 


\section{PENDAHULUAN}

Pendidikan memberikan harapan pada mahasiswa untuk memperoleh kesempatan dan pengetahuan agar dapat hidup lebih berkulalitas (lebih baik). Pendidikan adalah salah satu unsur penting dalam kehidupan manusia, pada satu fokus yang lebih khusus, yaitu pendidikan formal (sekolah atau perguruan tinggi), manusia diberikan dasar-dasar pengetahuan sebagai pegangan dalam menjalani hidup (Lovisia, 2019). Proses kegiatan belajar mengajar fisika kerap sekali dihadapkan pada sebuah materi yang abstrak. Pelajaran fisika masih terkesan sulit untuk dipahami karena memiliki konsep yang abstrak dan tidak mudah dihubungkan dengan kejadian sehari-hari dalam kehidupan manusia. Hal ini menuntut para pendidik untuk kreatif dalam menciptakan dan mengembangkan media-media pembelajaran agar siswa dapat lebih tertarik dalam mempelajari fisika dan materi yang disampaikan dapat benar-benar dimengerti oleh peserta didik. Faktor penghambat lainnya dalam belajar fisika adalah motivasi siswa tersebut dalam mempelajari materi-materi fisika. Hambatan ini termasuk dalam faktor internal. motivasi merupakan hasrat untuk belajar dari seorang individu. Kurangnya motivasi pada diri siswa menyebabkan seorang siswa tidak sungguh-sungguh atau kurang bersemangat dalam melaksanakan kegiatan sehingga terhambat dalam mencapai tujuan belajar. Apabila siswa tidak termotivasi maka siswa akan malas untuk memperhatikan pelajaran fisika yang disampaikan oleh guru, siswa tidak akan tertarik untuk mengajukan pertanyaan kepada guru terhadap hal-hal yang belum jelas dalam belajar fisika bahkan siswa akan kurang giat belajar agar mendapatkan nilai yang baik dalam mata pelajaran fisika. Upaya meningkatkan motivasi ini dapat dilakukan berbagai macam bentuk dan kegiatan. Satu diantaranya yang dapat memotivasi siswa adalah adanya media pembelajaran sebagai bentuk kongkret dari pengertian-pengertian konsep yang abstrak dan penjelasan fisis dari berbagai rumus (Haisy, M. C., Astra, I. M., \& Handoko, E, 2015).

Penggunaan media pembelajaran yang bervariasi dalam kegiatan belajar mengajar, cenderung dapat membangkitkan minat dan motivasi peserta didik untuk terlibat secara aktif dalam proses pembelajaran. Salah satu media pembelajaran yang dapat digunakan dalam mata pelajaran fisika adalah dengan menggunakan alat peraga. Alat peraga fisika mempunyai fungsi memvisualisasikan sesuatu yang tidak dapat atau sukar di lihat oleh siswa secara langsung sehingga dapat menjelaskan suatu ide pokok, prinsip kerja, gejala, atau hukum alam. Jika dilihat dari hakikatnya, alat peraga merupakan salah satu alternatif penyelesaian permasalahan peserta didik dan berfungsi juga sebagai alat untuk meningkatkan motivasi para siswa. Alat peraga merupakan salah satu ciri khas pembelajaran fisika yang dapat 
memotivasi siswa untuk mencapai proses pembelajaran yang optimal (Haisy, M. C., Astra, I. M., \& Handoko, E, 2015).

Selain permasalahan alat peraga sebagai media pembelajaran, persoalan kontekstual yang terjadi pada kehidupan dapat dibahas di dalam kelas oleh dosen dan dapat diupayakan penyelesaiannya dengan melakukan ide-ide kreatif atau inovasi dalam melakukan pembelajaran. Karena Cara mengajar menjadi penentu keberhasilan proses belajar mengajar (Trisna, N., \& Ariani, T, 2019). Inovasi tersebut dapat berupa penggunaan model, praktik secara langsung dan juga penggunaan metode pembelajaran tepat.

Penerapan pembelajaran dengan praktik secara langsung merupakan merupakan salah satu dari bagian inovasi pembelajaran yang memungkinkan mahasiswa lebih mudah untuk memahami materi yang diajarkan. Praktik adalah pelaksanaan secara nyata apa yang disebutkan dalam teori. Sedangkan alat praktikum adalah alat bantu proses belajar mengajar yang dapat dipergunakan untuk merangsang timbulnya pemikiran, perhatian dan kemampuan atau ketrampilan mahasiswa sehingga dapat membantu tercapainya tujuan dari pembelajaran. Pembelajaran dikatakan berhasil apabila proses belajar mengajar berhasil mencapai tujuan dari pembelajaran (Abdisa, 2012). Untuk mencapai keberhasilan dalam melakukan pembelajaran perlu dilakukan strategi yang tepat dalam melakukan pengajaran. Strategi pengajaran dapat berupa media, model, eksperimentasi atau praktikum dan lain sebagainya. Menurut (Wattimena, 2014) bahwa pembelajaran melalui praktikum dapat meningkatan pemahaman konsep-konsep dasar fisika mahasiswa untuk indikator mencontohkan, mengklasifikasikan, dan menjelaskan. Menurut (Rosariana dkk, 2016) yang menjadi keharusan dalam pembelajaran sains adalah adanya penguasaan konsep, kegiatan pembuktian melalu eksperimen dan aplikasinya dalam kehidupan. Pembelajaran melalui praktikum merupakan pembelajaran kognitif yang menciptakan situasi yang dapat membuat mahasiswa belajar aktif menemukan pengetahuan sendiri. Sehingga pembelajaran melalui praktikum sangat tepat digunakan dalam pembelajaran sains karena praktikum adalah proses belajar menemukan konsep melalui mengumpulkan data atau informasi yang diperoleh dari pengamatan, percobaan atau eksperimen untuk mendapatkan pengetahuan (Kyriazis dkk, 2009). Karena pengetahuan yang diperoleh dengan menemukan memungkinkan pengetahuan akan bertahan lama atau lebih mudah diingat dan dari beberapa penelitian menunjukkan bahwa model pembelajaran praktikum sangat unggul dan efektif untuk digunakan dalam pembelajaran, terutama untuk pembelajaran sains (Tompo dkk, 2016). 
Dari wawancara yang dilakukan peneliti pada mahasiswa baru di Universitas Bina Insan Lubuklinggau dipeoleh informasi bahwa masih banyak mahasiswa yang belum paham tentang gravitasi. Kurangannya pemahaman tersebut disebabkan karena siswa tidak melakukan praktikum. Hal ini terjadi karena waktu di sekolah fasilitas laboratorium Fisika yang masih tergolong minim sehingga siswa tidak bisa melakukan praktikum dan ada juga yang disebabkan karena alat- alat laboratorium Fisika disekolah sudah tidak berfungsi dengan baik. Gaya gravitasi bumi adalah kekuatan yang membuat bumi menarik objek ke pusatnya (Sani dkk, 2016). Menurut (Muller, 2018) pada garis lintang $86.71^{\circ}$ dan bujur $61.29^{\circ}$ di atas permukaan samudra artik memiliki percepatan gravitasi tertinggi $9,8337 \mathrm{~m} / \mathrm{s}^{2}$ di dunia. Dari $63 \%$ mahasiswa masih menganggap bahwa benda dengan massa yang lebih berat akan jatuh lebih cepat dari pada benda yang ringan. Menurut (Stylos dkk, 2008) sering terjadi kesalahan konsepdalam fisika bahwa benda yang massanya lebih berat akan jatuh lebih cepat dari benda yang massanya lebih ringan kesalahan tersebut disebabkan karena mereka hanya fokus pada pengamatan visual. Menurut (Taufiq, 2012) miskonsepsidapat diubah melalui pemberian pertanyaan, konflik kognitif, dan eksperimen pembuktian.

Seiring perkembangan teknologi dalam pembelajaran, dalam melakukan eksperimen fisika dapat menggunakan bantuan laptop sebagai alat pengambilan data yang lebih akurat. Karena didalam laptop terdapat kemampuan memvisualisasi berbagai fakta, keterampilan, konsep dan menampilkan gambar-gambar yang bergerak sesuai dengan keperluan (Coburn dalam Permana, 2012). Laptop semakin dikembangkan sebagai alat bantu pendidikan, baik di dalam kelas sebagai media penyaji pembelajaran maupun di laboratotium sebagai alat bantu eksperimental. Sebagai alat bantu eksperimen Laptop juga dilengkapi perangkat multimedia seperti soundcard. Soundcard memiliki microprocessor yang sering disebut Digital Sounds Processor (DSP). Digital Sound Processor memiliki fungsi mencuplik masukan analog dan mengubahnya menjadi data digital dan melakukan dekomposisi spektrum cahaya (Ishafit, 2012).Merujuk dari permasalaahan di atas sehingga pengembangansoundcard laptopsebagai alat praktikumsangat dibutuhkan untuk meningkatkan pemahaman mahasiswa pada konsep gerak jatuh bebas karena alat praktikum soundcard laptop merupakan alat pembelajaran yang terkomputerisasi sehingga lebih akurat. 


\section{METODE PENELITIAN}

Penelitian ini menggunakan metode pengembangan. Pada metode pengembangan digunakan model pengembangan ADDIE untuk mengembangkan alat praktikum dari soundcard laptop. Tahapan pengembangan ADDIE yaitu: analysis, design, development, implementation dan evaluating. Teknik pengumpulan data pada penelitian ini menggunakan angket. Angket digunakan untuk mengukur kelayakan pengembangan alat praktikum soundcard laptop. Angket diberikan kepada 3 ahli alat praktikum dan mahasiswa sebagi pengguna. Analisis validasi angket menggunakan skala likert dengan rentang nilai 1 sampai 5. Bobot pernyataan validasi angket ditunjukkan pada tabel 3.

Tabel 3. Bobot pernyataan validasi angket

\begin{tabular}{cc}
\hline Pernyataan & Bobot Peryataan \\
\hline Sangat Baik & 5 \\
Baik & 4 \\
Cukup & 3 \\
Tidak Baik & 2 \\
Sangat Tidak Baik & 1 \\
\hline
\end{tabular}

Perhitungan data nilai akhir hasil validasi dianalisis dalam skala (0-100) dilakukan dengan menggunakan rumus sebagai berikut :

$$
\text { Ketercapaian : } \frac{\text { Jumlah diperoleh }}{\text { Jumlah keseluruhan }} \times 100 \% \text { (1) }
$$

Data kuantitatifdari validator digunakan sebagai pertimbangan dalam melakukan revisi media untuk meningkatkan qualitas media atau alat praktikum (Fahrudin, 2018).Analisis kelayakan alat dipersentasekan mengikuti tabel 4 berikut:

Tabel 4. Kriteria validitas analisis nilai rata-rata

\begin{tabular}{cc}
\hline Skor & Kategori \\
\hline $80-100$ & Sangat layak/ sangat baik \\
$66-79$ & Layak/ baik \\
$55-65$ & Cukup/ Sedang \\
$44-54$ & Kurang layak \\
$33-43$ & Tidak layak \\
\hline
\end{tabular}




\section{HASIL DAN PEMBAHASAN}

Pengembangan soundcard laptop sebagai alat praktikum mengikuti model pengembangan ADDIE dengan tahapan analysis, design, development, implementation dan evaluating.

\section{a) Tahap analysis (kebutuhan)}

Penelitian pendahuluan dilakukan untuk mendapatkan informasi dan menganalisis permasalahan dan kebutuhan guru/dosen. Penelitian pendahuluan terdiri dari beberapa tahapan, yaitu: Langkah pertama, studi pustaka bertujuan mengumpulkan informasi dan teori yang berhubungan dengan permasalahan yang ada. Berdasarkan observasi yang telah dilakukan, sebagian besar mahasiswa baru Universitas Bina İnsan Lubuklinggau masih banyak yang belum paham tentang gravitasi. Gaya gravitasi bumi adalah kekuatan yang membuat bumi menarik objek ke pusatnya (Sani dkk, 2016). Pada garis lintang $86.71^{\circ}$ dan bujur $61.29^{\circ} \mathrm{di}$ atas permukaan samudra arktik memiliki percepatan gravitasi tertinggi $9,8337 \mathrm{~m} / \mathrm{s}^{2}$ di dunia. Dari $63 \%$ mahasiswa masih menganggap bahwa benda dengan massa yang lebih berat akan jatuh lebih cepat dari pada benda yang ringan, hal ini mendukung untuk dilakukan penelitian penggunaan soundcard laptop sebagai alat praktikumuntuk memahamkan tentang konsep grafitasi.

b) Tahap design

Pada perencanaan pengembangan dimulai dengan menentukan alat dan bahan yang akan digunakan untuk membuat alat praktikum. Berapa biaya yang dibutuhkan dan lama waktu pengerjaan juga diperhitungkan. Kemudian membuat gambar atau skema alat peraga, selanjutnya pembuatan alat peraga. Melalui instrumen akan diuji kevalidan, kepraktisan dan kefektifan alat peraga untuk digunakan di dalam proses KBM. Tahap desain merupakan tahap perancangan alat praktikum yang meliputi pembuatan desain alat secara keseluruhan.

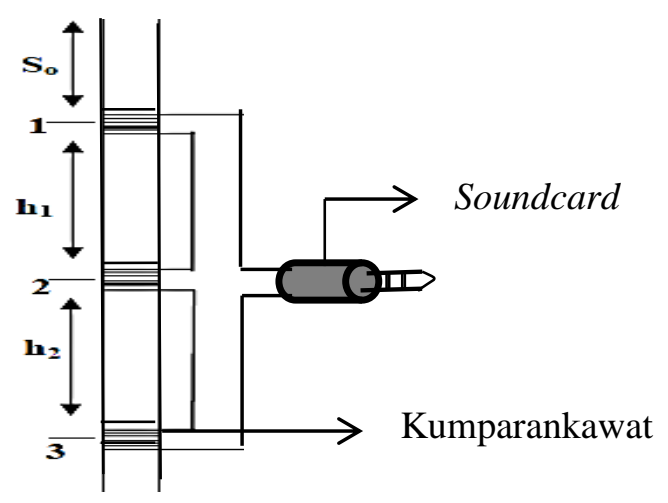

Gambar 1. Desain alat praktikum 


\section{c).Tahap development}

Alat peraga yang telah selesai dibuat kemudian melalui uji validasi oleh tenaga ahli. Uji validasi bertujuan untuk mengetahui validitas dari alat peraga yang dihasilkan. Kemudian alat peraga akan dievaluasi juga untuk melihat sejauh mana alat peraga bisa dan layak digunakan. Melalui evaluasi kelebihan dan kekurangan alat akan bisa diketahui dan sangat memungkinkan untuk dilakukan perbaikan sehingga media pembelajaran berupa alat peraga ini akan menjadi bagus. Setelah dilakukan perbaikan atau direvisi, barulah alat peraga bisa diimplemetasikan. Jika memungkinkan adanya evaluasi lagi dan direvisi kembali sampai media berupa alat peraga tersebut menjadi lebih bagus. Seluruh komponen yang telah dipersiapkan pada tahap desain kemudian dirangkai menjadi satu kesatuan sebagai alat praktikum. Gambar dari hasil gambar hasil pengembangan alat praktikum soundcard laptop ditunjukkan pada gambar 2 berikut.

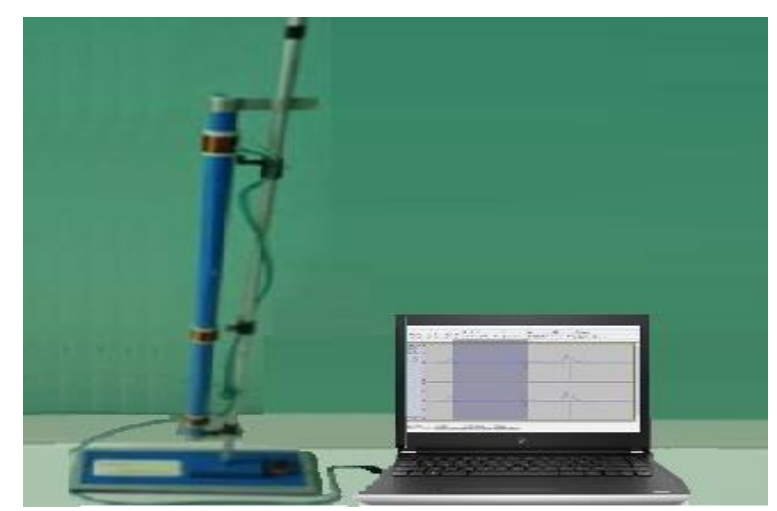

Gambar 2. Alat praktikum

Pada penelitian ini untuk meningkatkan pemahaman mahasiswa pada konsep gerak jatuh bebas menggunakan bantuan software audacity dan soundcard. Alat eksperimen ini dirancanguntuk meningkatkan pemahaman mahasiswa pada konsep gerak jatuh bebas. Dimana mahasiswa mampu menggambarkan grafik waktu yang dibutuhkan benda jatuh terhadap ketinggian, mampu menentukan nilai percepatan gravitasi bumi dan memberikan pemahaman mahasiswa tentang pengaruh massa benda terhadap waktu jatuh benda dan percepatan gravitasi. Semua aspek tersebut dapat diperoleh dengan melakukan variasi masa magnet. Ketika magnet dijatuhkan, waktu diukur darimunculnya pulsa pada saat magnet menginduksi lilitan. Dari pulsa tersebutdidapatkan waktu yang ditampilkan pada laptop dengan jarak lilitan dan masa yang telah ditentukan. Dari gambar 1 persamaan untuk menentukan nilai gravitasi adalah sebagai berikut 


$$
g=\frac{2\left(\frac{h_{2}}{t_{2}}-\frac{h_{1}}{t_{1}}\right)}{t_{1}+t_{2}}(2)
$$

Sedangkan presentase erorr relatif dapat dicari dengan prsamaaan berikut.

$$
\text { Erorr }=\left(\frac{g_{\text {ekssperimen }}-g_{\text {teori }}}{g_{\text {teori }}}\right) \times 100 \% \text { (3) }
$$

Adapun contoh hasil pengambilan data waktu ketika magnet dijatuhkan pada tampilan audacity dapat dilihat pada gambar 3.

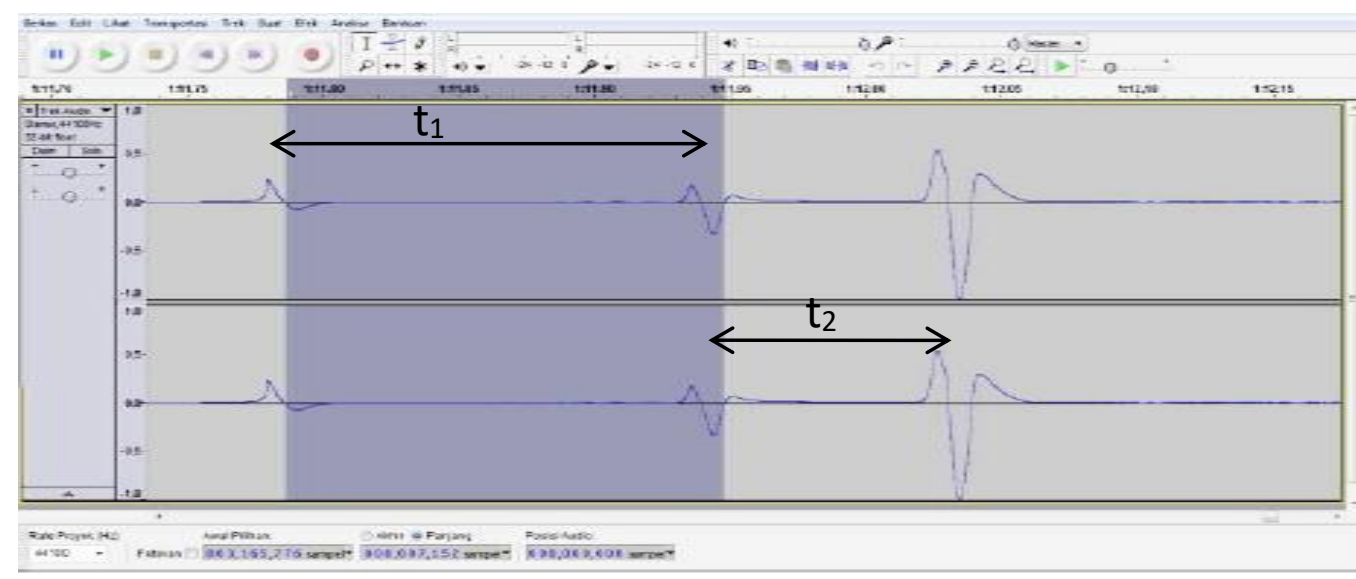

Gambar 3. Contoh waktu yang tampilkan pada audacity ketika magnet dijatuhkan

d) Tahap implementation

Penelitian ini diimplementasikan pada mahasiswa baru prodi teknik informatika Universitas Bina Insan Lubuklinggau tahun 2018/2019, sekaligus sebagai uji pengguna alat praktikum soundcard laptop. Adapun pelaksanaan praktikum ditunjukan pada gambar 4 berikut.

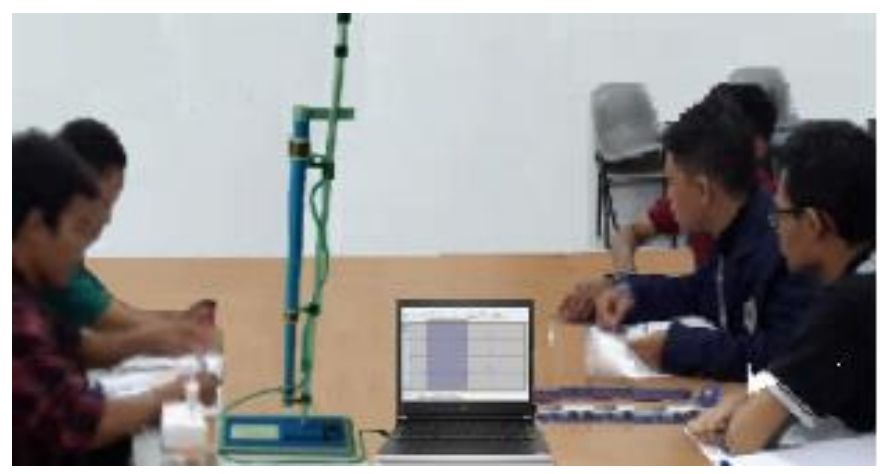

Gambar 4. Pelaksanaan praktikum

Adapun hasil praktikum salah satu klompok dengan menggunakan soundcard laptop ditunjukkan pada tabel 5 . 
Tabel 5 .Hasil praktikum penentuan percepatan grafitasi menggunakan souncad laptop

\begin{tabular}{ccccccc}
\hline No & $\begin{array}{c}\text { Sampel magnet } \\
(\mathbf{g r})\end{array}$ & $\mathbf{h} \mathbf{h}$ & $\mathbf{h} \mathbf{2}$ & $\boldsymbol{t}_{\mathbf{1}}$ & $\boldsymbol{t}_{\mathbf{2}}$ & $\boldsymbol{g}$ \\
\hline $\mathbf{1}$ & 50 & 0,414 & 0,396 & 0,1791380 & 0,0917890 & 10,07317 \\
$\mathbf{2}$ & 100 & 0,414 & 0,396 & 0,1740590 & 0,0933750 & 9,393391 \\
$\mathbf{3}$ & 150 & 0,414 & 0,396 & 0,1714060 & 0,0923890 & 9,434196 \\
$\mathbf{4}$ & 200 & 0,414 & 0,396 & 0,1788660 & 0,0919250 & 10,02536 \\
$\mathbf{5}$ & 250 & 0,414 & 0,396 & 0,1795010 & 0,0920410 & 10,03869 \\
$\mathbf{6}$ & 300 & 0,414 & 0,396 & 0,1821770 & 0,0917910 & 10,25896 \\
$\mathbf{7}$ & 350 & 0,414 & 0,396 & 0,1740590 & 0,0931750 & 9,437368 \\
\hline
\end{tabular}

Hasil rata-rata penentuan percepatan grafitasi dari seluruh sampel adalah $9,808 \mathrm{~m} / \mathrm{s}^{2}$.

Sedangkan hasil percepatan grafitasi pada permukaan samudra arktik memiliki percepatan gravitasi tertinggi $9,8337 \mathrm{~m} / \mathrm{s}^{2} \mathrm{di}$ duniaSedangkan presentase erorr relatif dapat dicari dengan prsamaaan 4. Adapun hasilnya sebagai berikut.

$$
\text { Erorr }=\left(\frac{9,808-9,832}{9,832}\right) \times 100 \%=2,33 \%
$$

Dari perhitungan erorr relatifdidapatkannilai erorr sebesar 2,33\% yang mennujukan bahwa alat praktikum souncard laptop memiliki akurasi tunggi karena data terkomputerisasi. Sedangkan erorr sendiri disebabkan karena kesalahan pada saat melakukan blok pada hasil waktu yangditunjukkan software audacity.

e) Evaluating.

Konten dan aspek alat praktikum setelah dibuat kemudian divalidasi untuk mengetahui qualitas alat praktikum. Setelah divalidasi oleh ahli konten alat direvisi sesui masukan dari para validator. Hasil validasi oleh ahli alat untuk mengetahui layak atau tidaknya alat praktikum dengan angket menggunakan skala penilaian 1 sampai 5 disajikan padagamabar 5 .

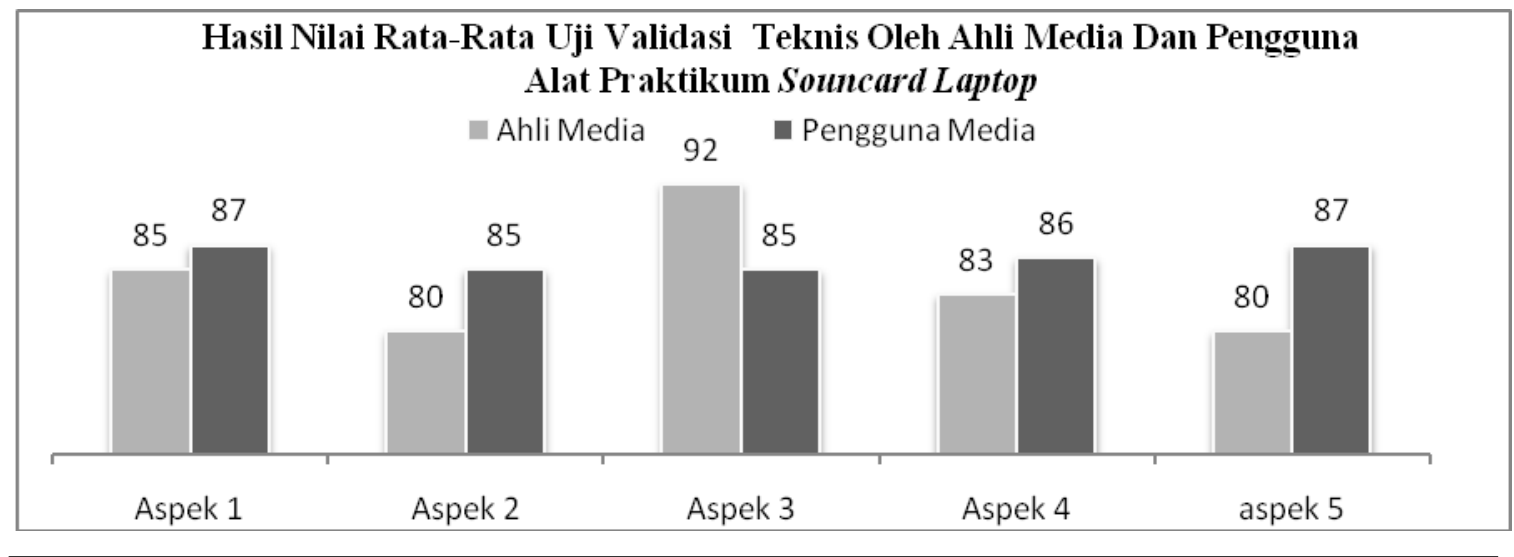

Gambar 5. Hasil nilai uji validasi teknis oleh ahli alat dan pengguna alat praktikum soundcard laptop 
Keterangan gambar 5 sebagai berikut.

Ahli Alat : Aspek 1.Kemenarikan

Aspek 2.Kepraktisan pemilihan alat dan bahan pada kegiatan eksperimen,

Aspek 3. Kesesuaian pemilihan alat praktikum dengan kegiatan eksperimen,

Aspek 4. Kondisi alat dan bahan dalam keadaan baik

Aspek 5. Tingkat keselamatan pengguna alat praktikumsaat kegiatan

pembelajaran

Uji penggunaa : Aspek 1. Kemudahan penggunaan alat dalam praktikum

Aspek 2. Alat praktikum sesuai dengan tujuan pembelajaran atau kompetensi

Aspek 3. Alat praktikum sesuai dengan materi ajar siswa

Aspek 4. Alat praktikumdapat menjelaskan konsep dengan baik

Aspek 5. Alat praktikummeumbuhkan rasa ingin tahu dan memotivasi untuk belajar

Dari hasil uji validasi nilai rata-rata nila dari semua aspek untuk ahli alat adalah $84 \%$ sedangkan nilai rata-rata untuk uji pengguna $86 \%$, hasil ini berada pada kriteria sangat layak digunakan sebagai alat praktikum.

\section{SIMPULAN}

Berdasarkan hasil pengembangan alat praktikum soundcard laptop didapatkan alat yang memiliki akurasi pengukuran perceptan grafitasi yang baik dengan error 2,33\%. Sedangkan hasil uji teknis kelayakan didaptkan hasil rata-rata validasi ahli adalah $84 \%$ sedangkan nilai rata-rata untuk uji pengguna $86 \%$.

\section{DAFTAR PUSTAKA}

Abdisa, G., \& Getinet, T. (2012). The effect of guided discovery on students' Physics achievement. Latin-American. Journal of Physics Education, 6(4), 530-537.

Coe, R. (2002). It's the Effect Size, StupidWhat effect size is and why it is important. British Educational Research Journal (BERJ),28(1), 9-16.

Dahlan, M.S. 2009. Statistik untuk Kedokteran dan Kesehatan, Edisi 4 (Deskriptif, Bivariat dan Multivariat, dilengkapi Aplikasi dengan Menggunakan SPSS).akarta: Salemba Medika 
Fahrudin, A. (2018). Development of Physics Summary Book as a SmartphoneBasedApplication and Its Effect on Elasticity Learning Achievement. Kasuari: Physics Education Journal (KPEJ), Vol 1, No. 1, Hal 22-33

Haisy, M. C., Astra, I. M., \& Handoko, E. (2015, October). Pengembangan Alat Peraga Resonansi dan Efek Doppler Berbasis Soundcard PC/Laptop untuk Meningkatkan Motivasi Belajar Fisika Siswa SMA. In PROSIDING SEMINAR NASIONAL FISIKA (E-JOURNAL) (Vol. 4, pp. SNF2015-II).

Ishafit. (2012). Teknologi Informasi dan Komunikasi dalam Pembelajaran Fisika:Komputerisasi Eksperimen Bunyi Berbasis Soundcard Laptop. Prosiding SeminarNasional Fisika UNJ 2012.Jakarta: UNJ.

Kyriazis, A., Psycharis, S., \&Korres, K. (2009). Discovery Learning and the ComputationalExperiment in Higher Mathematics and ScienceEducation: A Combined Approach. International Journal of Emerging Technologies in Learning (iJET), 4(4), 25-34.

Lovisia, E. (2019). PENERAPAN METODE EKSPERIMEN TERHADAP HASIL BELAJAR FISIKA SISWA KELAS XI SMA NEGERI 2 MUARA BELITI. SILAMPARI JURNAL PENDIDIKAN ILMU FISIKA, 1(2), 114-120.

Muller, H. (2018). Quantum Gravity Aspects of Global Scaling and the Seismic Profile of the Earth.Progress In Physics, 4(1), 41-45.

Permana, I., \&Rohma, I. (2012).Visualization Multimultimedia To Enhance Concepts Understanding And Generic Science Skills Of Vocational High School Students On The Hydrocarbons Concept. Jurnal Pengajaran MIPA (JPMIPA), 17( 1), 132-141.

Rosariana, G., Sudin, A.,\& Sujana, A. (2016). Penerapan Model Discovery Learning untuk Meningkatkan Hasil Belajar Siswa pada Materi Perubahan Wujud Benda. Jurnal Pena Ilmiah, 1(1), 371-380

Sani, H. M., Baraya, T. J., Mu'awuya, M. S., \&Abdulkarim, A.(2016). Comparison of Theoretical and Measured Acceleration Due to Gravity.International Journal of Innovative Research in Science, Engineering and Technolog (IJIRSET).5(3),3787-3797.

Stylos, G., Evangelakis, A. G., \& Kotsis, T. K. (2008). Misconceptions on classical mechanics by freshman university students: A case study in a Physics Department in Greece. Themes In Science And Technology Education, 1(2), 157-177.

Taufiq, M. (2012). Remediasi Miskonsepsi Mahasiswa Calon Guru Fisika PadaKonsep Gaya Melalui Penerapan Model Siklus Belajar (Learning Cycle) 5E. Jurnal Pendidikan IPA Indonesia(JPII), 1 (2) 198-203. 
Tompo, B., Ahmad, A., \& Muris, M. (2016).The Development of Discovery-Inquiry Learning Model to Reduce the Science Misconceptions of Junior High School Students. International Journal Of Environmental \& Science Education, 11(12), 5676-5686.

Trisna, N., \& Ariani, T. (2019). Model Direct Instruction Dengan Teknik Probing Prompting: Dampak Terhadap Hasil Belajar Fisika Siswa Kelas X SMA Negeri 4 Lubuklinggau Tahun Pelajaran 2018/2019. SILAMPARI JURNAL PENDIDIKAN ILMU FISIKA, 1(1), 24-37.

Wattimena, H.S, Suhandi. A, \& Setiawan. A (2014). Pengembangan Perangkat Perkuliahan Eksperimen Fisika Untuk Meningkatkan Kreativitas Mahasiswa Calon Guru Dalam Mendesain Kegiatan Praktikum Fisika Di Sma, Jurnal Pendidikan Fisika Indonesia, 10 (2) 128-139 